\title{
SC|A?
}

\section{Mulheres, pesquisa e produção científica em tempos de isolamento social: entre o sentir, $o$ cuidar e o tecnológico}

\author{
Aliana França Camargo Costa ${ }^{1}$ \\ Kátia Morosov Alonso ${ }^{2}$
}

\section{Resumo}

O isolamento social provocado pela Covid-19 trouxe uma espécie de disrupção em nossas vidas. Reinventar-nos neste processo ao mesmo tempo em que a vida nos convida a reflexão esta posto dentro do que compreendemos ser o estilo desta época - o estético. Assim, este artigo intenciona buscar horizontes na perspectiva do ideal comunitário, na cultura do sentir, na cultura do cuidado e como todos nós estamos enredados pelo tecnológico a partir do contexto da cultura digital, na qual se forma a sociedade em rede. Para observar o que está ocorrendo do lado de cá do isolamento social de uma pós-graduanda, refletimos sobre a utilização do celular, um artefato tecnológico muito presente na vida dos indivíduos. Ao contemplar o mundo, pensando em suas complexidades, nos damos a possibilidade de renegociar as condições postas neste cenário de intensas reformulações sociais.

\section{Palavras-chave}

Isolamento social. Mulheres. Pesquisa. Sentir. Tecnologia.

Recebido em: 31/07/2020

Aprovado em: 26/01/2021

${ }^{1}$ Doutoranda em Educação pelo Programa de Pós-graduação em Educação da Universidade Federal de Mato Grosso. Membro do grupo de pesquisa Laboratório de Estudos Sobre Tecnologia da Informação e Comunicação na Educação - LêTece.

E-mail: alianacamargo@gmail.com

${ }^{2}$ Doutora e docente associada da Universidade Federal de Mato Grosso. Docente do Programa de Pós-Graduação em Educação - PPGE - do Instituto de Educação da UFMT. Líder do Grupo de Pesquisa Laboratório de Estudos Sobre Tecnologias da Informação e Comunicação na Educação - LêTECE.

E-mail: katia.ufmt@gmail.com 


\section{Women, research and scientific production in times of social isolation: between feeling, caring and technology}

\section{Abstract}

The social isolation caused by Covid-19 has brought a kind of disruption to our lives. Reinventing ourselves in this process at the same time that life invites us to reflect is placed within what we understand to be the style of this time - the aesthetic. Thus, this article intends to seek horizons in the perspective of the community ideal, in the culture of feeling, in the culture of care and how we are all entangled by technology from the context of digital culture, in which network society is formed. To observe what is happening on this side of the social isolation of a graduate student, we reflect on the use of cell phones, a technological artifact very present in the lives of individuals. When contemplating the world, thinking about its complexities, we give ourselves the possibility to renegotiate the conditions placed in this scenario of intense social reformulations.

\section{Keywords}

Social isolation. Women. Cientific search. To feel. Technology. 


\section{Primeiras palavras}

Há aproximadamente 12 mil anos, desde a revolução agrícola, a maior parte das civilizações no mundo estão ancoradas no pensamento patriarcal, na visão em que o homem é o chefe, tendo, portanto, a voz mais forte e valorizada na comunidade.

Embora este artigo seja sobre a vivência cotidiana das mulheres no contemporâneo, voltamos o olhar para este processo histórico-social a fim de compreendermos que, se o patriarcado é algo que configura nossas relações sociais disso resulta que o pensar, o educar, pensar e o agir se põem nesse contexto. Ainda que exista e permaneça o modo feminino nos âmbitos antes indicados, tais ações são submetidas à estrutura social a que nos referimos, sendo que até recentemente cruzar ou questionar essa fronteira consistia em algumas exceções corajosas.

As diferenças entre o homem e a mulher podem ser respondidas por distinções biológicas, como gerar um filho ser correspondente ao corpo feminino. Contudo, algumas visões impediram e cercearam a mulher de ocupar certos cargos e posições em sociedade; visões baseadas em ideias, normas e no imaginário cultural do que propriamente em uma base biológica, conforme Harari (2018). Tanto é assim em diferentes e distintas culturas há obrigação, em maior ou menor grau, de que as mulheres concretizassem em suas existências a reprodução, não estando no horizonte das sociedades patriarcais esta recusa. Incluindo nisso a ideia de que o primogênito deveria ser um varão, ou seja, um bebê biologicamente do sexo masculino. Não raro em narrativas de diferentes mídias e atores sociais, isso em pleno século XXI, há o reforçamento de tal pressuposto: ter uma menina poderia ser fruto de uma "fraquejada", por exemplo.

O gênero, no imaginário humano constituído historicamente, haveria divisão em duas categorias: homens e mulheres. Os papéis de cada um deles são marcados pelos mitos culturais, de um lado a especificidade masculina garantiria participação na vida política, o direito de votar e o dever de atender o 
seu país através do serviço militar, entre tantos outros, e por outro lado o mito para o feminino como aquele que lhe atribui a criação dos filhos, de ser protegida contra violência, disso advindo a obediência ao marido, pais e autoridades em geral. Nenhum desses papéis está destituído de suas cargas sociais e exigências. Na sociedade patriarcal o homem precisa confirmar, desde cedo, sua masculinidade e virilidade, enquanto a mulher "deve, continuamente, convencer a si mesma e aos demais que é feminina o bastante" (HARARI, 2018, p. 207).

Na construção de sua tese sobre a breve história da humanidade em Sapiens, Harari (2018) não elucida a questão da estabilidade do sistema patriarcal e do aprisionamento do sexo feminino por milhares de anos, mas aponta a colaboração que marcou a trajetória feminina:

Como foi que, em uma espécie cujo sucesso depende sobretudo de cooperação, os indivíduos supostamente menos colaborativos (homens) controlaram os indivíduos supostamente mais colaborativos (mulheres)? Até o momento presente, não temos uma resposta satisfatória. (HARARI, 2018, p. 218).

Apesar da desdita histórica da mulher, no final do século XIX, começamos a observar uma revolução feminina mais perceptível: como a perceber o seu corpo dentro do contexto social, a se imaginar em cargos e profissões antes dominadas pelo sexo masculino. No caso do Brasil, a educação foi uma das principais portas sociais para que a mulher passasse a olhar para a sua história e a sua condição.

Esse é um mote importante na constituição do presente artigo, por meio da educação mais e mais mulheres conquistam espaços sociais relevantes. Com esta afirmação não se ignora que outros espaços de atuação e convocação às mulheres não sejam significativos nas transformações que vimos verificando nas ultimas décadas: os movimentos sociais, os coletivos, entre outros exemplos, apóiam e fortalecem lutas que impliquem maior protagonismo feminino. De toda maneira, consideramos aqui que o processo educativo/formativo tem denotado possibilidades bastante promissoras no marcador de espaços e tempos que corroboram maior participação da mulher 
nos contextos sociais, políticos e econômicos na medida em que as empodera. Diante disso, a reflexão aqui evidenciada, parte da vida de uma mulher, mãe, pesquisadora, que em momento do isolamento social se vê 'enredada' por diferentes relações mediadas, necessariamente, pelas tecnologias da informação e comunicação (TIC), instalada em contexto no estilo do nosso tempo - o estético. As mudanças drásticas impostas pela pandemia da Covid-19 fez com que nos reorganizássemos de tal modo que as redes comunitárias possibilitadas pela janela digital nos ajudaram a não sucumbir nos "altas e baixos" da psique humana configurado pelo atual cenário do isolamento.

Além disso, pensaremos como as redes de afiliação digitais, vivenciadas por meio de artefatos tecnológicos, se intensificaram na pandemia; trataremos sobre a cultura do cuidado como possibilidade de cooperação; bem como de experiência com recorte de dez dias do uso do celular por meio do aplicativo "Bem-Estar Digital"3 para observar como as TIC estão presentes na vida de uma pós-graduanda em nível de doutoramento, cujo grupo ao qual pertence tem como proposta estudar as TIC na educação. Por fim, finalizando o presente texto, refletiremos sobre a revolução do papel da mulher no mercado de trabalho, na economia do cuidado, de sua relação com a sociedade em rede, e como o atual cenário inspira pensar neste futuro de sucessivos 'agoras'.

\section{Estética e vida feminina no século $X X I$}

O isolamento social causado pela pandemia do coronavírus é tido como uma disrupção em nossas vidas e trabalho, nos enredando em cotidianos outros manifestados em nossas relações sociais.

Para este momento, nos lançamos a contemplar o mundo, ao modo como nos ampliou Michel Maffesoli (1995) para o qual o estilo de uma época nos traz algumas respostas do que buscamos na angústia corriqueira do isolamento. Portanto, entrelaçaremos aqui dois pontos de vista: a sociológica e a filosófica

3 O aplicativo Bem-estar digital, criado pela Google e lançado no início de 2019, permite que o usuário possa acompanhar o tempo e o uso do celular, observando a sua relação com o artefato tecnológico. Através desta observação o usuário poderá tomar decisões para melhorar nos aspectos de uso e qualidade de vida, por exemplo. 
para tentar descortinar esse emaranhado de redes ao qual estamos todos ligados.

A reflexão com olhar sociológico intenta chegar o mais próximo da vida social e para isso vamos nos aprofundando em sucessivos ensaios que jamais são concluídos, pois sendo uma semiose da vida cotidiana, não podem ser explicados em sua totalidade, mas uma incursão ao pensar no aqui e agora, delimitando suas características essenciais. A escrita, à sua maneira, é sempre um contraponto do campo social, e este é sempre tributário de sua época.

A vida concreta é refletida desde as primeiras horas do raiar do sol até a abstração de sua consciência. Mas quando uma nova forma de cultura está em curso é necessário "adotar uma postura intelectual que, com flexibilidade, contenta-se em descrever, em registrar, em "monstrar" o que é. Ainda que, por muitos de seus aspectos, este estado de coisas seja monstruoso" (MAFFESOLI, 1995, p. 14). E no estilo em que nos encontramos há um aspecto importante para compreender a formação comunitária de nossas vidas:

O ideal comunitário também se encontra nas várias formas de solidariedade ou de generosidade, cuja análise muitas vezes se negligencia. Estas podem ser mais ou menos espetaculares, ser vividas discretamente na vida quotidiana (MAFFESOLI, 1995, p. 16).

O ideal comunitário está ancorado em duas palavras: estilo e imagem. Ao trabalhar essas duas palavras-chave, um pensamento complexo se desenrola em imagens, no imaginário, no simbólico, no jogo das aparências, e estes ocupam todos os lugares da realidade empírica.

Contraponto desta visão comunitária é a projeção do narcisismo e do individualismo na contemporaneidade, ao modelo de uma vida líquida, no qual a distinção entre quem consome e seus objetos de consumo estão em plano momentâneo e efêmero (BAUMMAN, 2007). Como uma espécie de coisificação da vida, uma reversão de papéis, ou na mistura e fusão entre objeto e consumidor. 
Neste mesmo sentido, Adorno (1995) trata sobre o conceito de consciência coisificada para dizer que pessoas e coisas tornam-se iguais. Esse conceito recebe influência marxista devido ao mecanismo da troca e à estrutura da mercadoria, tornando a relação humana em "coisa":

No que diz respeito à consciência coisificada, além disto, é preciso examinar também a relação com a técnica, sem restringir-se a pequenos grupos. (...) Por um lado, é certo que todas as épocas produzem as personalidades - tipos de distribuição da energia psíquica - de que necessitam socialmente. Um mundo em que a técnica ocupa uma posição tão decisiva como acontece atualmente, gera pessoas tecnológicas, afinadas com a técnica; isto tem a sua racionalidade boa: em seu plano mais restrito elas serão menos influenciáveis, com as correspondentes consequências no plano geral. Por outro lado, na relação atual com a técnica existe algo de exagerado, irracional, patogênico. Isto se vincula ao "véu tecnológico". Os homens inclinam-se a considerar a técnica como sendo algo em si mesma, um fim em si mesmo, uma força própria, esquecendo que ela é a extensão do braço dos homens. Os meios - e a técnica é um conceito de meios dirigidos à autoconservação da espécie humana - são fetichizados, porque os fins - uma vida humana digna - encontram-se encobertos e desconectados da consciência das pessoas. (ADORNO, 1995. P. 132)

Vejamos, Adorno (1995) recorre a pensar na dualidade da utilização do tecnológico em uma época em que a televisão estava no seu auge, em que a indústria cultural ditava os caminhos de grandes sociedades, era um momento de comunicação um com todos, exemplificando a verticalização da voz e do poder. Vivemos, porém, em tempo distinto, embora a explanação do autor contribua para pensarmos em nosso estilo, em nossa época e como nos enredaremos com a intensidade que a tecnologia ocupa na trama das nossas vidas durante e também pós-pandemia. Por esta oportunidade de pensar a existência que Bauman (2007) nos avisa de nossa participação consciente visto que "a desatenção à vida em comum impede a possibilidade de renegociar as condições que tornam líquida a vida individual” (BAUMAN, 2007, p. 20).

Não sabemos ainda como a fetichização da técnica ocupa lugar na mente dos indivíduos, qual é o ponto de transição de uma relação racional do uso da técnica e a qual supervalorização leva a atitudes de barbárie, de ódio e opressão (ADORNO, 1995). 
O que sabemos agora é que a forma gregária, o comunitarismo em rede esboça o nosso estilo, conceito que demarca uma época. Assim como na Idade Média a crença inseria Deus no centro das relações sociais, sendo a pauta para os costumes e práticas; a modernidade esteve marcada pelo fator econômico; $\mathrm{o}$ nosso tempo contemporâneo tem como centro de seu estilo a estética, esta definida pela sua etimologia - o sentir. Dada essas demarcações o que se observa é que uma época não está destituída da historicidade da outra, pois no avançar das sociedades os estilos se encontram com o que está em atividade.

Em suma, a humanidade viveu e ainda vive uma época de transição. Os eventos que se apresentam ajudam a compreender a especificidade do estilo contemporâneo, e este está envolto de sincretismo, isso quer dizer que antigas práticas não foram deixadas de lado. Na transição de estilos há sobreposição “em uma mistura de gêneros e na reutilização multiforme de elementos dos 'bons e velhos tempos"' (MAFFESOLI, 1995, p. 27).

O sentimento de pertencimento, da participação, envolve os "mistérios" do grupo. Esse "mistério" é a estetização da vida, o sentir, forma pela qual se partilha com o outro e se estabelece como cimento das nossas relações, sejam elas com o ambiente social ou com o ambiente natural.

Esse estar-junto se configura no vitalismo juvenil, nos gostos sexuais, religiosos, culturais, no político. E mesmo que haja a força da agregação, existem também atração e a repulsão ao diferente como exclusão, formando segmentações, isso traz para o plano social o equilíbrio cenestésico, uma espécie de "equilíbrio conflitual, onde o bem e o mal, o verdadeiro e o falso, a função e disfunção conseguem compor entre si” (MAFFESOLI, 1995, p. 55).

Todas as forças opostas, as ideologias, as questões religiosas, os dogmas contraditórios, as imagens que circulam estão obrigados a estar num mesmo plano de co-presença, a suportarem-se, negociam, entram em contato por territórios reais ou simbólicos. 
A imagem é o que nos liga, é o resultado, um conjunto provocado pela existência do imaginário presente no corpo social. Assim como o totem foi a ligação para as tribos primitivas, a imagem por sua vez é um pólo que liga as tribos na contemporaneidade, um elemento de comunhão. De forma que as imagens podem ser as cinematográficas, as esculturais, pictóricas, arquitetônicas, tecnológicas, escritas, uma infinidade de representações.

A força do imaginário tem elementos que vem do racional, mas tem parâmetros que apresentam a sua energia como a fantasia, o afetivo, o não racional, os sonhos, o onírico, o lúdico, e esses elementos formam as construções mentais do corpo social na sua vida prática. Essas dimensões do imaginário condicionam a construção do espírito e esta influencia as práticas, que estão enlaçadas pelo emocional e pelo afeto. Assim, "O imaginário é também a aura de uma ideologia, pois, além do racional que a compõe, envolve uma sensibilidade, o sentimento, o afetivo. (MAFFESOLI, 2001, p. 4”.

Um exemplo que podemos tratar para compreender como o imaginário opera é quando olhamos para o percurso da mulher, especificamente aquela que se tornou mãe, e sobretudo considerando este imaginário por grande parte da humanidade. Roland Barthes (2015) consegue decifrar, enquanto pensa na imagem como reprodução óptica (humana) e técnica (máquina), a expressão de um signo, a imagem materna, enquanto produtora de sentido. É dele uma das passagens mais significativas dessa 'deidade' na esfera social:

Dizem que o luto, por seu trabalho progressivo, apaga lentamente a dor: eu não podia, não posso acreditar nisso; pois, para mim, o Tempo elimina a emoção da perda (não choro), isso é tudo. Quanto ao resto, tudo permaneceu imóvel. Pois o que perdi não é uma Figura (a Mãe), mas um ser; e não um ser, mas uma qualidade (uma alma): não a indispensável, mas a insubstituível. Eu podia viver sem a Mãe (todos vivemos, mais cedo ou mais tarde); mas a vida que me restava seria infalivelmente e até o fim inqualificável (sem qualidade). (BARTHES, 2015, p. 67)

O mundo imaginal é causa e efeito de uma "subjetividade de massa" que, progressivamente, contamina todos os domínios da vida social. Ao nos encontrarmos na cultura do sentimento pensamos em suas causas e efeitos 
dentro do corpo social. Além da subjetividade que atravessa o coletivo pelo campo do imaginário, precisamos refletir que a saturação do ideal democrático deu lugar ao senso de comunidade como um projeto a ressignificá-lo no sentido de uma nova significação vivida com o outro, e que esse quadro também passa a ser causa e efeito de uma nova maneira de estar-junto.

Uma economia do si que caminha para integra-se na economia do mundo, como sinergia do sentimento de pertencimento, também é um dos elementos da causa e efeito das sociedades contemporâneas. "É nesse sentido que se pode falar do estilo da época: no caso, um estilo estético" (MAFFESOLI, 1995, p. 57).

Como o sentir é democrático ele atravessa diferentes camadas sociais, diversas categorias profissionais, ultrapassa as classes. É nesta transversalidade que o estilo estético se firma como a "democracia da vida".

\section{Estética, cotidiano e hedonismo}

Na estética do viver o hedonismo está muito presente. Há hedonismo na forma como nos relacionamos com o corpo, com as imagens (vide os vários memes que nos direciona para uma espécie de ironia cotidiana), com os objetos, com os espaços, e com tudo o que isso representa a materialidade da vida. $\mathrm{E}$ toda essa forma como nos relacionamos é algo partilhado, formando uma união mística, uma verdadeira comunhão.

Com o hedonismo atravessando os modos de viver, o corpo é visto como um projeto de cuidar de si, a busca por estar livre, pela qualidade de vida como objetivo. Neste sentido, o filósofo Espinosa (2000), que antecedeu os iluministas, já nos alertava que somente os homens livres poderiam ser gratos um com os outros, e ao sermos livres, como mulheres que somos, percebemos o nosso corpo. De forma que este corpo é constituído primeiramente pela alma, e tudo o que acontece com a alma afetará seu objeto (corpo), assim "nada poderá acontecer nesse corpo que não seja percebido pela alma”. (ESPINOSA, 2000, p. 234) Compreendendo que o conceito da alma forma uma coisa pensante, é o próprio pensamento. 
Assim vivenciados, o corpo e o sexo estão para além do sentido de pecado, da culpa, e ocupa no imaginário outra lógica do dever-estar neste mundo contemporâneo. É com esta transição de estilo que o ambiente familiar estável e tradicional começou a ser diluído no inicio da crise de representação (BUCKINGHAM, 2003). Isto fez com que o status da mulher passasse para outra esfera, situando a sua figura de mulher, antes recuada para o espaço privado do lar, para um projeto de multifunções sociais - mulher, mãe, chefe de família, empreendedora, pesquisadora, e o que mais ela se permitir sonhar.

O hedonismo tribal enlaça a vontade de se embelezar para mostrar ao outro, como uma aceitação do outro, uma aprovação, e antes que seja apontado como individualismo, Maffesoli (1995) irá defender que essa nova forma de estar com outro de maneira gregária caminha no sentido da epifanização do corpo, a vontade do ócio, da liberdade, do culto ao corpo, do esporte, do cuidado de si como um projeto de estar com o outro, fazendo sentido se o outro também está incluso neste processo.

Assim, vai se constituindo o hedonismo na vida cotidiana, uma espécie de "vida subterrânea", com sua importância para a formação individual porque se constitui como o húmus de que faz desenvolver o curso da vida. Por meio deste cotidiano que nos empreendemos nas ações, relações, pensamentos, situações anódinas, eventos importantes, assuntos, objetos interligados em uma rede sutil e ao mesmo tempo complexa, convertida para dentro e para fora no sentido da globalidade, do todo.

E todos os processos que envolvem a rede sutil do cotidiano tem a origem no que é chamado de lar. Neste lugar se faz o eco global a partir do que está dentro; os gestos, as linguagens, as vestimentas, as atrações tribais, as emoções coletivas, estilos de vida para o qual cada indivíduo não escapa.

A estética, portanto, funciona como o fio condutor na contemporaneidade que dá forma ao totem da mulher, mãe, pesquisadora, professora, cuidadora em um tempo de desafios, de negação da ciência por parte do governo vigente, da reinvenção de si para um projeto educativo do aqui e agora. 


\section{O cuidado, o comunitarismo e as relações tecnológicas}

Na perspectiva do doméstico o indivíduo pode estabelecer uma alternativa ao político, pois pode resistir às diversas imposições dos poderes e das instituições. Ao desbancar o mito do ideal democrático que vigoraram na modernidade, Maffesoli (1995) dirá que a cultura do sentimento estabelece relações mais afetivas e emocionais do que racionais,

quer seja pela doçura, pela indiferença ou pela abstenção, a socialidade em questão sabe se fazer ouvir. Até mesmo seu silêncio é eloquente, e não deixa, atualmente, de provocar suores frios nos diversos responsáveis políticos, sindicais e administrativos (Ibid, 1995, p. 69)

O estilo estético tende a favorecer o estar-junto e cultivar o que se pode chamar de "cuidado de si" e busca no sentido dado a formação da tribo, encontrar o outro e partilhar emoções e sentimentos que lhes são comuns:

\footnotetext{
Esse "cuidado de si", como dizia Michel Foucault, não era de nenhuma maneira sinônimo de retração sobre si mesmo, mas ao contrário, iria influir amplamente na relação com os outros: vida conjugal, atividades cívicas, relações econômicas e até mesmo, evidentemente, a relação com a natureza. Assim, a questão do prazer ou da busca do hedonismo eram uma postura social original, uma maneira específica de se comportar em relação ao ambiente natural e ao ambiente social, em suma, determinariam uma "estilística da existência". (MAFFESOLI, 1995, p. 70)
}

Atualmente, existem múltiplas possibilidades na sistematização e definição que diz repeito ao conceito de cuidado, a saber: a diferenciação entre trabalho produtivo e reprodutivo; da divisão ou junção do cuidado de pessoas e trabalho doméstico; a equidade de gênero como promotor do bem viver (IPEA, 2016). Dentre as abordagens possíveis nosso intento é fazer uma incursão pelo conceito de cuidado e perceber em meio ao isolamento provocado pela pandemia, as relações entre o uso da tecnologia, o cuidar do lar, o cuidar de si, o papel da mãe, da mulher, pós-graduanda e como isso tudo se enlaça neste momento ímpar na qual todos nós vivemos. 
A cultura do cuidado já vem sendo amplamente discutida na esfera social e ganhou espaço na academia nos últimos 40 anos. O conceito de cuidado é um conjunto de valores e uma série de práticas concretas indispensáveis para a existência humana. $\mathrm{O}$ cuidar se traduz em tarefas que são meios e fins para o que hoje compreendemos como a era da sustentabilidade. Pensar o cuidado deve ser voltado para a subsistência no plano social, econômico e ambiental (SCHILDBERG, 2015). A limitação de um debate sobre o tema impacta nos estímulos às capacidades e na liberdade de mulheres, e de toda a esfera social homens, crianças, idosos.

Na cultura do cuidado, a educação desempenha um papel fundamental dentro do processo. Portanto, na ação que desenvolve o imaginário da cultura do cuidado a necessidade esta sempre à frente do desejo. Uma dessas ações está vinculada no combate a desigualdades, no qual se propõe uma equidade de gênero, em corresponsabilidades familiares compartilhadas, o objetivo é conscientizar que a vida familiar e profissional são inerentes a homens e mulheres, e o Estado não está destituído de sua responsabilidade social nesta articulação (IPEA, 2016).

O imaginário que se forma em torno do conceito de cuidado é o eco do estilo estético que, para além dos domínios das artes, permeia o conjunto da vida social, como maneira de sentir e de experimentar em comum, um processo de correspondência do ambiente social e ambiente natural.

A concepção feminista que traz para a discussão atual justamente o questionamento que Harari (2018) nos apontou, é de uma sociedade mais colaborativa, baseada em suas redes de afiliação. A direção aponta para uma cooperação que ajude a manter, continuar e reparar o mundo para que ele possa ser um lugar melhor. Um mundo que inclui os corpos, as individualidades, o ambiente, e que esses elementos sejam entrelaçados na complexa rede que sustenta toda a vida (SCHILDBERG, 2015). Neste momento recuperemos Espinosa (2000) que, ao rechaçar a dualidade corpo e alma, indica uma das premissas desta vida - a de que o eu e o ambiente social ao qual pertencemos forma uma unidade. Existe uma força holística na qual tudo deve ser olhado 
pelo conjunto e não somente em unidades separadas. É neste sentido que adotamos o termo vivência, quando relacionamentos o ambiente social e a pessoa que o percebe e o interpreta, dessa relação surge o "entre", a realidade vivenciada. (PRESTES, 2010)

Nas últimas décadas a força gregária vem crescendo impulsionada pela utilização das TIC. As culturas do sentimento e do cuidado fazem parte do que entendemos por cultura digital, um momento em que a tecnologia está amplamente disseminada formando a sociedade em rede.

A cultura digital trouxe impactos nas expressões culturais, nos sistemas de crenças, como interagimos com as pessoas, na desterritorialização das nossas identidades, em processos de comunicação que hoje, no interior do lar, onde vivemos o isolamento social, causa a implosão de linguagens, imagens, imaginários.

A tecnologia digital é um produto da cultura digital e suas engrenagens atribuem elementos para a digitalização da vida (GERE, 2008). Tornamo-nos assim, praticantes culturais ao construir dentro do nosso cotidiano todos os nossos laços e relações atravessados pelo artefato tecnológico, um habitus que toma proporção central e sustenta o que explica a atual condição das estruturas da sociedade contemporânea (CERTEAU, 1998). Por esta perspectiva nos lançamos a observar a nossa prática cultural junto ao uso do celular.

\section{A cultura digital do lado de cá do isolamento social}

A última publicação do Instituto Brasileiro de Geografia e Estatísticas (IBGE) sobre os dados de uso da internet e das Tecnologias da Informação e Comunicação - TIC (2018) apontou que $98 \%$ da população usam o celular. Deste universo, As mulheres são as que mais usam a rede com com 75,7\% frente aos $76,3 \%$ dos homens.

Outra pesquisa realizada pela Google e publicada pela Folha de São Paulo (05 de junho de 2020) demonstrou o crescimento do uso de celulares durante a 
pandemia. O estudo revelou que quem passou a usar mais o artefato tecnológico foram as mulheres: com $65 \%$ contra os $56 \%$ dos homens. Mulheres com idades entre 35 e 44 anos, comparados a mesma faixa etária que os homens, usaram ainda mais os celulares $-70 \%$ frente aos $45 \%$ do público masculino.

A facilidade do uso e a possibilidade de ser a extensão de nossas mãos configurou o celular como o daemon 4 da fabulosa história da Bússola Dourada de Philip Pullman (2002), na analogia que trazemos para a discussão o artefato tecnológico se insere na sinergia que existe entre o homem e a máquina. Essa junção é o que forma a extensão de nossa mente, os sistemas que processam a informação e promovem a comunicação são considerados tecnologias da psique ou psicotecnologias, como denominado por Kerckhove (2009), nos indicou que os artefatos tecnológicos, como o celular, se configuram como a nossa própria pele, dentro de uma cultura cada vez mais digital. A união homem-máquina encontrou pulsão dentro do isolamento social, realidade que ainda estamos tentando entender: quais distopias encontrarão materialidade? Quais aspectos psicológicos estão se formando?

Da pesquisa do Google, três atividades que nunca foram vivenciadas começaram a fazer parte da vida dos pesquisados no isolamento como: aulas online (17\%), videochamadas (16\%) e as lives (15\%). De uma hora para outra tivemos que mudar de cenário rapidamente, e o que era privado passou a ser público pelas lives de salas virtuais como o Meet ou o Zoom. Na educação, professoras que já acumulavam funções no que era considerado o cotidiano normal, tiveram que se adaptar para gravar, editar, reformular as estratégias de ensino passando da aula presencial para a aula online. $\mathrm{O}$ momento exige um despertar para o aprender a aprender em uma dinâmica distinta da que estávamos envolvidas.

Outros dados do Google revelaram algo que já sentimos do lado de cá desta tela: 66\% das pessoas já pensam em fazer um "detox digital”; 61\% estão cansados de

4 No livro, Philip Pullman insere o daemon como uma espécie pertencente aos humanos. Cada pessoa que nasce tem o seu daemon, um animal que durante a infância toma outras formas, mas na vida adulta se estabelece a uma única forma escolhida. Assim, o daemon é o próprio ser, ele fala, pensa, tem emoções e pode sentir o sentimento do seu humano e vice-versa. 
usar os celulares durante o isolamento; $60 \%$ se sentem sobrecarregadas com o consumo de tantas informações; entretanto, $75 \%$ se sentem gratos por ter no celular uma janela para o mundo, um alento para os dias de confinamento.

Na esteira dessa pesquisa resolvemos investigar a relação com o celular por meio do aplicativo Bem-estar digital, lançado pela Google no início de 2019. O objetivo era identificar a quantidade de horas e quais os principais apps acessados pela pós-graduanda no período de 10 dias, (entre 14 e 23 de julho de 2020), com mais de três meses de vivência no isolamento social. Os dados podem nos indicar a relação com o 'artefato celular' dentro do isolamento, permitindo fazer algumas reflexões dessa observação. A experiência foi realizada com a pós-graduanda desta escrita, casada, mãe de dois filhos pequenos, com 37 anos de idade. Embora a experiência seja direcionada para 0 uso do celular, outras telas que não estão nos achados também foram utilizadas no cotidiano como a Smart TV e o notebook.

O aplicativo Bem-estar digital possibilita acompanhar o tempo de uso dos apps instalados no celular, a frequência que o usuário utiliza o smartphone, quantas notificações recebe, permitindo que pessoa perceba o seu hábito no uso do artefato, o que pode ajudar a impor limites quando considerar necessário e evitar os excessos.

Durante o período de observação o aparelho celular recebeu 5.602 notificações, sendo mais de $90 \%$ delas por meio do Whatsapp, um aplicativo popular no Brasil que recebe e envia informações como mensagens de texto, áudio e vídeo. Este aplicativo foi o segundo mais utilizado, totalizando 11 horas e 33 minutos de uso (média de 1hora e 13 minutos por dia) do Whatsapp. As redes de afiliação a qual a pós-graduanda pertence são diversificadas, como: grupo de maternidade, na qual mães se ajudam mutuamente na descoberta de melhores informações para a educação de seus filhos; de yoga, na intenção de trazer qualidade de vida e corpo/mente saudável; grupos de família; de reflexão do cenário político brasileiro; grupos de estudos da pós-graduação a qual pertence; de mulheres (doulas) que buscam o respeito ao parto no país; de produtores de vídeo; de amigos do tempo da faculdade. 
O YouTube ficou em primeiro lugar na preferência da utilização dos aplicativos consumindo 20 horas e 32 minutos do tempo da pesquisadora. Nesta escolha esta a profusão de lives que tem tomado importância no cotidiano, da crescente produção, difusão e da cultura do compartilhamento de vídeos nos últimos anos, intensificada durante a pandemia. No total, a tela do celular foi olhada, consumida, consultada durante mais de 81 horas nos 10 dias da experiência, isso dá a média de 8 horas/dia em que o artefato esteve em evidência. Somado a isso, o cuidado com os filhos (principalmente com o seu psicológico), as refeições diárias, a organização do lar, o pensamento positivo de que a vida nos exige coragem.

Neste fluxo contínuo e avassalador de imagens, informações, signos, códigos, linguagens, Maffesoli (1995) advoga que a ideologia egocêntrica caiu em desuso e não circula no seio social com a força que ora provocava, porque o princípio empírico está nas formações comunitárias, nas relações comunicacionais. $\mathrm{O}$ contexto contemporâneo é essencialmente plural, polissêmico, e a comunicação se torna afetiva, ao estilo estético. Dentro desta perspectiva encontramos a autocomunicação de massa, no qual as pessoas detêm o poder de se comunicar como todos em uma esfera horizontal, quebrando a lógica anterior, ancorada na verticalidade. Essa forma de comunicação foi possível por meio da sociedade em rede, na qual podemos fazer um movimento de contrapoder a quem ditava o poder na esfera vertical.

Neste sentido, as práticas de comunicação estão cada vez mais diversificadas e forma o multiculturalismo que povoa a internet. É neste contexto que Castells (2015) nos chama a atenção para o comunalismo que ao se fundir com a identificação fluida da diversidade de comunidades culturais trará transformações nos valores e crenças voltados para o bem coletivo e que firmará como uma democracia em um novo espaço da cidadania global. 


\section{Mulher, trabalho e a economia do cuidado}

Desde a revolução na qual o punho da mão para cima clamava Igualité, fraternité, liberte vem brotando nas mulheres o sentimento de que poderiam ocupar espaços no qual pudessem se expressar e interagir com mais voz, poder e dignidade.

No entanto, há muitas lutas dentro do espaço de trabalho que, em momento de transição para uma sociedade informacional, nos desafia a compreender quais as mudanças afetam a vida das mulheres. Sabemos que as transformações desta nova estrutura social combinam três afirmações: a atividade econômica deixa de ser a produção de bens e passa para a lógica de serviços; há surgimento de novas profissões administrativas e especializadas com grande conteúdo de informação e conhecimentos em suas atividades; os empregos tradicionais como os rurais e o da indústria estão escassos ou em declínio irreversível. Neste sentido, refletiremos sobre o papel da mulher dentro dessa nova conjuntura da realidade em uma cultura digital.

Importante contextualizar neste cenário de transformação para a nova economia que surge a partir da década de 1990, que a pressão feminina formou importante revolução não só na ocupação de espaços de trabalho, mas na redução da diferença salarial - "a incorporação das mulheres foi fundamental para o desenvolvimento da nova economia com consequências duradouras para a estrutura familiar e social." (CASTELLS, 2003, p.79)

As características para o novo ambiente de trabalho podem ser olhadas da seguinte maneira: primeiro, a capacidade de aprender a aprender é um grande trunfo, já que as informações ficam obsoletas, pois tudo está em constante mudança de forma rápida; segundo, a capacidade de transformar a informação por meio do processo de aprendizado em conhecimento específico. Desta forma, a luta pela educação de seu país é um ato de resistência e, sobretudo, de sobrevivência diante da nova conjuntura. 
Na reflexão sobre a Sociedade em Rede, Castells (1999) nos chamava a atenção para a tendência de flexibilização do trabalho que vivemos intensamente no isolamento social. Nessa transformação, quatro elementos formam o esquema do novo trabalho: a flexibilidade na jornada de trabalho, não se restringindo ao tradicional turno de 40 horas; o trabalho desempenhado por tarefas, não garantindo a estabilidade e permanência futura no emprego; a localização do trabalho, não necessariamente no local do trabalho, mas em casa, no trânsito; por fim, mudanças no contrato social entre patrão e empregado, este está bem representado pela atual reforma trabalhista brasileira no qual o compromisso dos empregadores não são os mesmos com os tradicionais direitos dos empregados.

Na dimensão estética, o trabalho pelo trabalho, visão essencial da ideologia produtiva, tende a ficar farta do proselitismo que ressoa do utilitarismo. $\mathrm{O}$ estético alia, ainda que de forma opaca, a criação com o prazer, na importância das interações afetivas e do cooperativismo:

(...) pode-se dizer que o estilo estético do quotidiano contamina um domínio que até então era submetido ao princípio de realidade puramente econômico, e a uma organização racional, da qual o taylorismo era a expressão acabada (MAFFESOLI, 1995, p. 72).

Portanto, a mudança eficiente que agregue o sentimento colaborativo e de cooperação, no sentido que nos impulsiona a pensar pelo viés feminino, foi e ainda é uma das diferenças para a revolução do corpo social e para o que caracteriza a economia do cuidado. Ainda que pareça nebuloso, no quadro está posto: de um lado a realidade da globalização capitalista, e do outro a esperança de uma transformação social e econômica pelo viés da sustentabilidade e cuidado. Precisamos olhar, em meio ao isolamento social provocado por um vírus, para a nossa condição humana. Desta perspectiva "é necessário um novo sistema econômico e social, onde as noções normativas de liberdade, a expansão das capacidades humanas, o cuidado, a equidade social e de gênero sejam tão importantes quanto a sustentabilidade ambiental. (SCHILDBERG, 1995, p. 6) 
Alguns temas práticos sobre o cultura do cuidado se referem a uma aplicação que atravessa a economia vinculada a sustentabilidade e o cuidado, como procurar estabelecer processos vitais entre natureza e seres humanos e pensar nas consequências no longo prazo e se antecipar a elas.

Neste novo sistema econômico, a compreensão é de que a remuneração e valorização precisam estar alinhadas e adequadas para as atividades formais e informais, e elas devem se voltar para o cuidado de crianças, adultos dependentes, seres não-humanos e meio ambiente. Por meio de suas vozes, as mulheres querem se fazer ouvir no intento de assegurar o desenvolvimento das capacidades humanas, na expansão das liberdades e apoiando a vida para o bem coletivo do planeta.

\section{Referências}

ADORNO, Theodor W. Educação e Emancipação. $3^{\text {a }}$ edição. Trad. Wolfgang Leo Maar, Rio de Janeiro: Paz e Terra, 1995.

BARTHES, Roland. A câmera clara: nota sobre a fotografia. Trad. Júlio Castañon Guimarães. Ed. Especial. Rio de Janeiro: Nova Fronteira, 2015.

BAUMAN, Zygmund. Vida líquida. Tradução Carlos Alberto Medeiros. Rio de Janeiro: Jorge Zahar Ed., 2007

BUCKIMGHAN, David. Crescer na era das mídias: após a morte da infância. Tradução Gilka Girardello e Isabel Orofino. Florianópolis, 2006.

CAMILLO, Mateus. Uso de smartphones cresceu na pandemia e mudou forma como mulheres, idosos e mais pobres se conecta. Folha de São Paulo, São Paulo, 05 jun. 2020. Disponível em:

https://hashtag.blogfolha.uol.com.br/2020/06/05/uso-de-smartphonescresceu-na-pandemia-e-mudou-forma-como-mulheres-idosos-e-mais-pobres$\underline{\mathrm{se}-}$

conectam/?pwgt=kuf6lgjavox5s96rjiiuerggtbaoijvkxagj1dprv12upcle\&utm sou

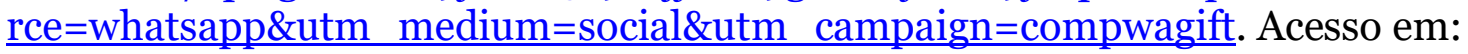
07 de jun. de 2020.

CASTELLS, Manuel. A sociedade em rede. A era da informação: economia, sociedade e cultura. Trad. Roneide Venâncio Majer. $6^{\mathrm{a}}$ ed. São Paulo: Paz e Terra, 1999.

CASTELLS, Manuel. A galáxia da internet: reflexões sobre a internet, os negócios e a sociedade. Trad. Maria Luiza X. de A. Borges; revisão técnica Paulo Vaz. Rio de Janeiro: Jorge Zahar Ed., 2003. 
CASTELLS, Manuel. O poder da comunicação. Trad. Vera Lúcia Mello Joscelyne. $1^{0}$ ed. São Paulo/Rio de Janeiro: Paz e Terra. 2015.

ESPINOSA, Baruch de. Ética. Partes III, IV e V. Trad. Joaquim Ferreira Gomes e Antônio Simões. São Paulo, SP: Ed. Nova Cultural. Coleção Os pensadores. 2000.

GERE, Charlie. Digital Culture. Reaktion Books: London. Second Editon, 2008.

HARARI, Yuval Noah. Sapiens: uma breve história da humanidade. Trad. Janaína Mascoantonio. Porto Alegre, RS: L\&PM, 2018. 592 p.

INSTITUTO BRASILEIRO DE GEOGRAFIA E ESTATÍSTICA. Acesso à internet e à televisão e posse de telefone móvel celular para uso pessoal 2018. Rio de Janeiro, 2020. 12 p. Disponível em:

https://biblioteca.ibge.gov.br/index.php/bibliotecacatalogo?view=detalhes\&id=2101705. Acesso em: 07 maio 2020.

IPEA - INSTITUTO DE PESQUISA ECONÔMICA APLICADA. Economia dos cuidados: marco teórico-conceitual. Relatório de pesquisa. Rio de Janeiro: Ipea, 2016.

KERCKHOVE, Derrick de. A pele da cultura: Investigando a nova realidade eletrônica. São Paulo: Annablume, 2009. 250 págs.

MAFFESOLI, Michel. A contemplação do mundo. Porto alegre: Artes e Ofícios ed. 1995.

MAFFESOLI, Michel. O imaginário é uma realidade. Entrevista concedida a Juremir Machado da Silva, em Paris, em 20 de mai de 2001. Porto Alegre: revista Famecos, $\mathrm{n}^{0}$ 15. 2001.

PRESTES, Zoia Ribeiro. Quando não é quase a mesma coisa: Análise de traduções de Lev Semionovitch Vigotski no Brasil, repercussões no campo educacional. Orientadora: Dr ${ }^{\mathrm{a}}$ Elizabeth Tunes. Tese apresentada ao Programa de Pós-Graduação em Educação da Faculdade de Educação da Universidade de Brasília/UnB. 2010.

PULLMAN, Philip. A bússola dourada. Rio de Janeiro: Objetiva, 2002.

SCHILDBERG, Cäcilie at all. Uma economia para o cuidado e a sustentabilidade: nota conceitual a partir de uma perspectiva feminista. A Fundação Friedrich Ebert. São Paulo, Sp: Análise. 2015. 